\title{
Supramolecular Chemistry. Supramolecular Rectangles and Their Guests
}

\author{
Andrew J. Goshe, B. Bosnich* \\ Department of Chemistry, The University of Chicago, 5735 S. Ellis Ave., Chicago, IL 60637, USA \\ Fax +1 (773) 7020805; E-mail: bos5@ midway.uchicago.edu \\ Received 12 January 2001 \\ This paper is dedicated to Ryoji Noyori, exceptional scientist, remarkable man.
}

\begin{abstract}
Two molecular spacers which cofacially dispose terpyridyl-palladium(II)-acetonitrile units separated by $\sim 7 \AA$ are described. The spacers are polyaromatic molecules, one spacer is fully aromatic whereas the other has two symmetrically disposed reduced aromatic rings. Addition of the linker, 4,4'-dipyridyl, to solutions of these spacer-chelator complexes leads to the rapid and quantitative formation of supramolecular rectangles. It is found that the reduced rectangle forms a 4:1 adduct with 9-methylanthracene whereas the oxidized rectangle forms a 5:1 adduct with 9-methylanthracene. The possible reasons for this high level of agglomeration and the difference in adduct formation for the two systems are discussed.
\end{abstract}

Key words: supramolecular chemistry, molecular recognition, palladium, $\pi-\pi$ interaction, host-guest chemistry

Unlike their purely organic analogues, supramolecular systems assembled by metal-ligand bonds present a number of advantages which are not readily available in organic molecules. Among these are the variety of valence directionalities that metals can possess, the number of available stable oxidation states and the ability to vary the charge of the supramolecular assembly. The most useful characteristic of metal complexes, however, is that in many cases metal-ligands bonds are (thermodynamically) stable but (kinetically) labile. This contrasts with organic systems where the bonds are both stable and non-labile. Consequently, the assembly of organic supramolecular structures is usually kinetically controlled whereas metal based analogues form under thermodynamic control. Thus, with inorganic systems, it is possible to encode in the structures of the kinetically stable ligands the information necessary for thermodynamic assembly of particular supramolecular structures. Although the principles of ligand encoding are at an early state of development, some remarkable successes have been reported.

Three basic approaches have been adopted in the synthesis of metal-based supramolecular structures. The simplest of these involves the mixing of a metal salt with a ligand of a particular structure to form an extended crystal structure. ${ }^{1}$ The product that is formed is controlled by the metal, the counter ion, the ligand and by the solubility of the product. Consequently, in most cases the method suffers from a lack of predictability. Another approach is the formation of complexes with oligo-bidentate or tridentate ligands. This method is usually predictable and has led to the isolation of molecular helicates and grids. ${ }^{2}$ Perhaps the most successful approach is that of Fujita $^{3}$ who used square planar complexes with two labile cis coordination sites. By the use of a variety of linking ligands, it was pos- sible to isolate a variety of large structures which incarcerated one or more guest molecules.

Our approach resembles some of these strategies but embodies distinct elements which are illustrated by the spacer-chelator palladium(II) complexes, 1 and 2. ${ }^{4}$ The cofacial terpyridyl-Pd-L (terpy-Pd-L) units are separated by $\sim 7 \AA$, a separation sufficient to incarcerate an aromatic molecule ${ }^{5}$ or square planar complex. ${ }^{6}$ The 3,5-di-tert-butyl-phenyl group was incorporated to provide solubility. Ligand, L, can be an anionic ligand or a neutral leaving ligand such as acetonitrile. When $\mathrm{L}=\mathrm{Cl}$, the $\mathrm{PF}_{6}^{-}$salts of $\mathbf{2}$ are very insoluble, those of $\mathbf{1}$ are soluble in aprotic solvents such as acetonitrile. Both $\mathbf{1}$ and $\mathbf{2} \mathrm{PF}_{6}{ }^{-}$salts of the acetonitrile complexes are soluble.

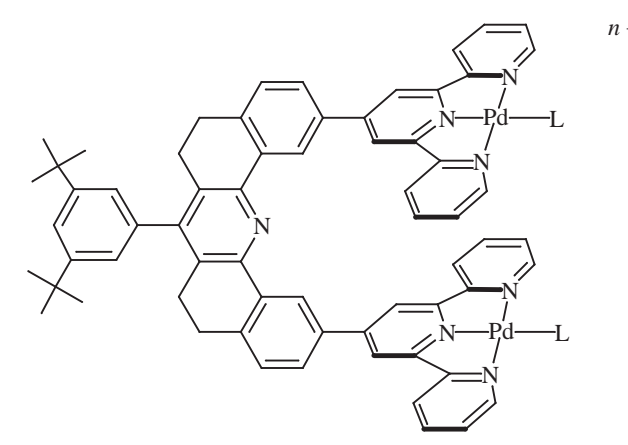

1

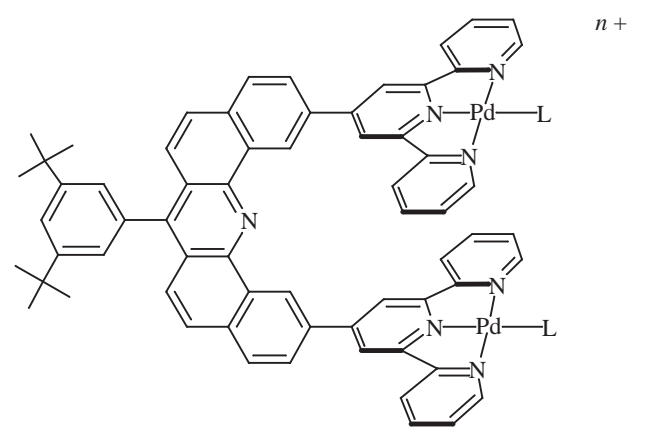

2 


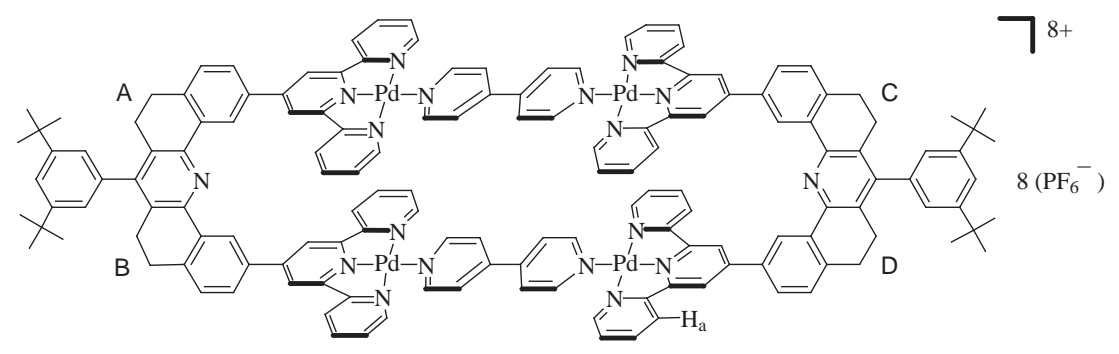

4

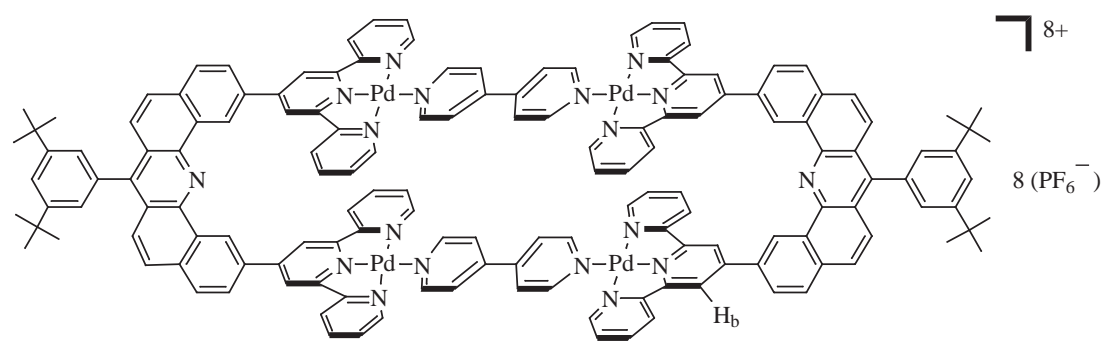

5

When either $\mathbf{1}$ or $\mathbf{2}$ ( $\mathrm{L}=$ acetonitrile) are mixed with the linear linker, 4,4'-dipyridyl, $\mathbf{3}$, in acetonitrile solutions at $25^{\circ} \mathrm{C}$, the corresponding molecular rectangles, $\mathbf{4}$ and $\mathbf{5}$ are formed within a few minutes and can be isolated in quantitative yield. ${ }^{7}$ This rapid self-assembly of $\mathbf{4}$ and $\mathbf{5}$ contrasts with their rates of assembly of the Fujita systems which, for palladium, can take hours to reach equilibrium although their rates may depend on the rates of dissolution of insoluble ligands. Presumably, in the cases of $\mathbf{4}$ and $\mathbf{5}$ the assembly rate is promoted by having fewer elements to combine and by the predisposed rigidity of the spacerchelator complexes.

The molecular rectangles, $\mathbf{4}$ and $\mathbf{5}$, were examined for their ability to act as receptors for various guests. We report here the results obtained for the guest, 9-methylanthracene (9-MA). All of the guest-host associations were performed in deuterated acetonitrile solutions at $23{ }^{\circ} \mathrm{C}$. The "mole-ratio" method ${ }^{8}$ for stoichiometry determination was used by observing the variations in ${ }^{1} \mathrm{H}$ NMR chemical shifts for certain protons of both the guest and host. Where significant chemical shifts were observed for either guest or host, plots of the change in chemical shift $(\Delta \delta)$ for either the guest or host versus mole ratio gave consistent results. Examples for such plots for $\mathbf{4}$ and $\mathbf{5}$ are shown in Figures 1 and 2 where it will be noted that the receptor, 4, associates with four 9-MA molecules whereas, $\mathbf{5}$, forms a 5:1 adduct. Guest-host association is signaled by a color change from yellow to red. Figure 3 shows the absorption spectra of the guest, hosts and those of the association complexes. It is clear that a new or modified existing electronic absorption band at around 20,000 $\mathrm{cm}^{-1}$ appears for the adducts.

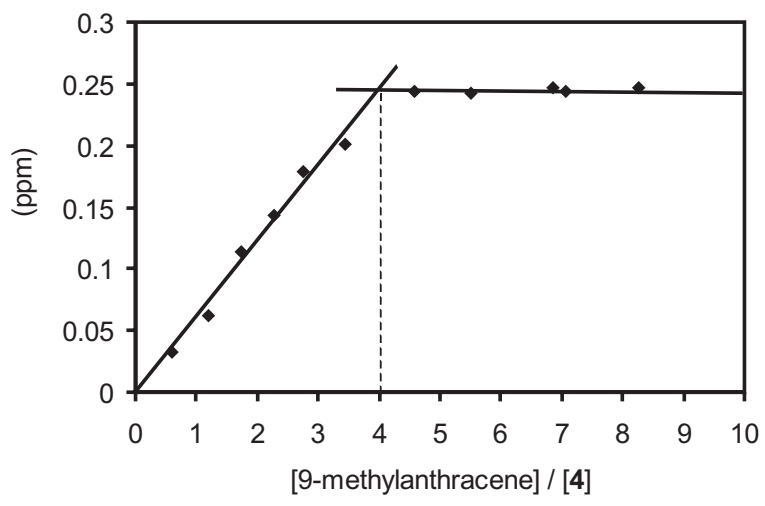

Figure $1{ }^{1} \mathrm{H}$ NMR determination of the stoichiometry of the adducts formed by 4 with 9-MA. The plot refers to the protons $H_{a}$ as indicated on 4.

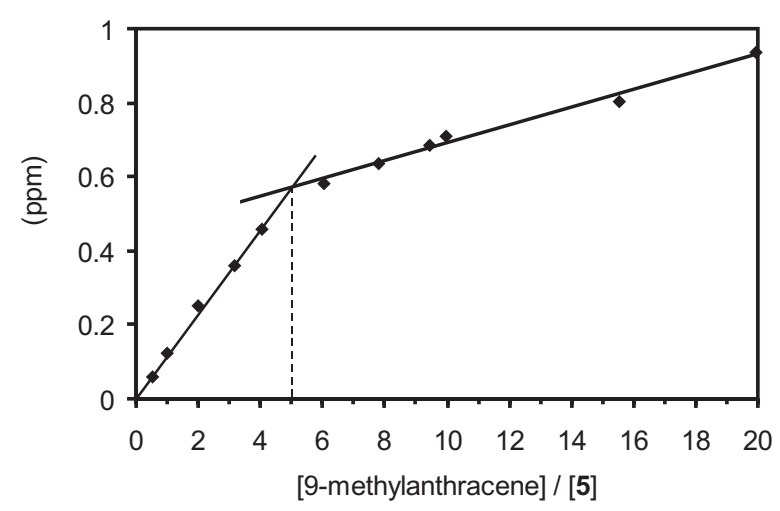

Figure $2{ }^{1} \mathrm{H}$ NMR determination of the stoichiometry of the adducts formed by $\mathbf{5}$ with 9-MA. This plot refers to the protons $\mathrm{H}_{\mathrm{b}}$ as indicated on $\mathbf{5}$. 


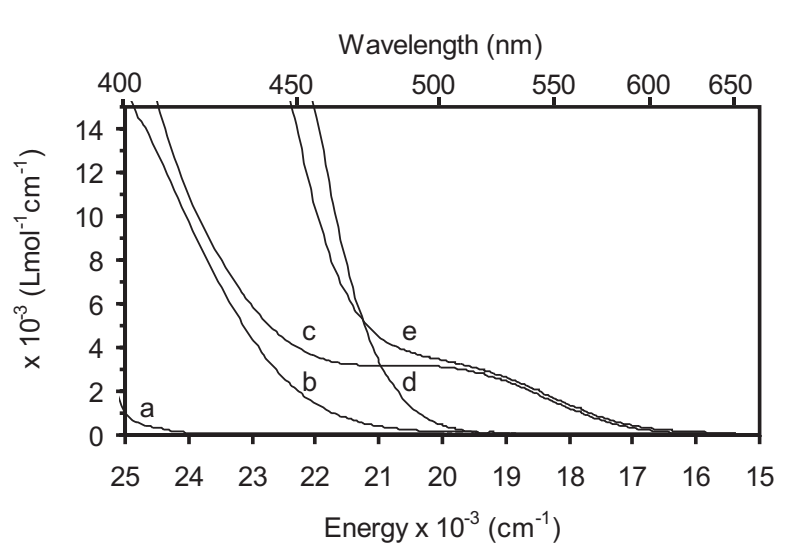

Figure 3 Absorption spectra for (a) 9-MA, (50.0 mM), (b) 4, (2.24 $\mathrm{mM})$, (c) a solution of $\mathbf{4}(2.24 \mathrm{mM})$ and 9-MA $(105 \mathrm{mM}),(\mathrm{d}) \mathbf{5}(2.43$ $\mathrm{mM})$, and (e) a solution of $\mathbf{5}(2.43 \mathrm{mM})$ and 9-MA (104 $\mathrm{mM})$.

Although it was not possible to estimate the association constants with any degree of accuracy because of the complexity of fitting four or five stability constants, it is remarkable that $\mathbf{4}$ and $\mathbf{5}$ form such high aggregates in dilute solution $\left(\sim 10^{-3} \mathrm{M}\right)$. An indication of the nature of these adducts may be inferred from a crystal structure of the 9-MA adduct of $[\mathbf{1}(\mathrm{L}=\mathrm{Cl})]^{2+}$ which was recently determined. ${ }^{4}$ The receptor $[\mathbf{1}(\mathrm{L}=\mathrm{Cl})]^{2+}$ crystallizes with two 9-MA molecules and in acetonitrile solutions it also associates with two 9-MA molecules. The crystal structure of $[\mathbf{1}(\mathrm{L}=\mathrm{Cl})]^{2+} \cdot 2(9-\mathrm{MA})$ is shown in Figure 4 where it will be noted that one 9-MA molecule resides in the molecular cleft whereas the other lies outside the cleft. In the extended crystal, however, this latter 9-MA is cofacially associated ( $\pi$-stacked) with the outside face of a terpy-Pd$\mathrm{Cl}$ unit belonging to a neighboring molecule. Whereas it would be expected that, in solution, the outside 9-MA molecule would have a much greater dissociation constant than the one in the cleft, experiment indicates that the inside 9-MA is only twice as stable as the outside-stacked 9MA. These observations permit us to suggest a structure for the 5:1 complex formed by 9-MA and $\mathbf{5}$. We propose that the 9-MA association with 5 consists of two 9-MA molecules within the two molecular clefts and that two 9-MA molecules are associated with the outer faces of the terpy-Pd-units of the molecular rectangle. Since the four outer terpy-Pd-faces of $\mathbf{5}$ are equivalent, it is possible that the 9-MA molecules engage in fluxional exchange between the sites. The ${ }^{1} \mathrm{H}$ NMR spectra indicate that the association complex is symmetrical on an ${ }^{1} \mathrm{H}$ NMR time scale. The fifth associated 9-MA molecule could also occupy one of the outer faces of a terpy-Pd-unit or, more likely, it could be incarcerated between the coparallel 4,4'-dipyridyl linkers of 5.

Although the molecular rectangles, $\mathbf{4}$ and $\mathbf{5}$, appear to be very similar, the $4: 1$ association of $\mathbf{4}$ indicates that association is controlled by subtle effects. The two reduced rings of $\mathbf{1}$ can exist in chiral conformation ( $\delta$ and $\lambda$ ) and, conse- quently, $\mathbf{1}$ can exist in racemic $(\delta, \delta$ or $\lambda, \lambda)$ or meso $(\delta, \lambda)$ forms. The crystal structure (Figure 4 ) shows that the molecule is in the racemic conformation. In solution, ${ }^{1} \mathrm{H}$ NMR spectroscopy shows a single set of proton signals indicating that either the racemic and meso forms interconvert rapidly or that one form exists exclusively. When the molecular rectangle, $\mathbf{4}$, is formed, these conformations can, in principle, generate additional isomers. The four energetically distinct forms are: $\mathrm{A} \delta, \mathrm{B} \delta, \mathrm{C} \delta, \mathrm{D} \delta$ (and the enantiomer); $\mathrm{A} \delta, \mathrm{B} \delta, \mathrm{C} \lambda, \mathrm{D} \lambda ; \mathrm{A} \delta, \mathrm{B} \lambda, \mathrm{C} \delta, \mathrm{D} \lambda ; \mathrm{A} \delta, \mathrm{B} \lambda, \mathrm{C} \lambda, \mathrm{D} \delta$ (see 4). The ${ }^{1} \mathrm{H}$ NMR spectrum of 4 shows one set of signals which may represent one single form or rapidly interconverting isomers. These conformational isomers of the two spacers in $\mathbf{4}$ cause the whole supramolecule to adopt conformations which follow those of the spacer. It is probable that these overall conformations influence the receptor capacity of $\mathbf{4}$. We suppose that the 9-MA adducts of $\mathbf{4}$ involve two 9-MA molecules in the two molecular clefts with the other two molecules stacking on the outer faces of the terpy-Pd-units. It is possible that, as a result of the twisting of the molecular rectangle, a 9-MA molecule cannot be incorporated between the two 4,4'-dipyridyl linkers as was proposed for the more rigid molecular rectangle, 5 .

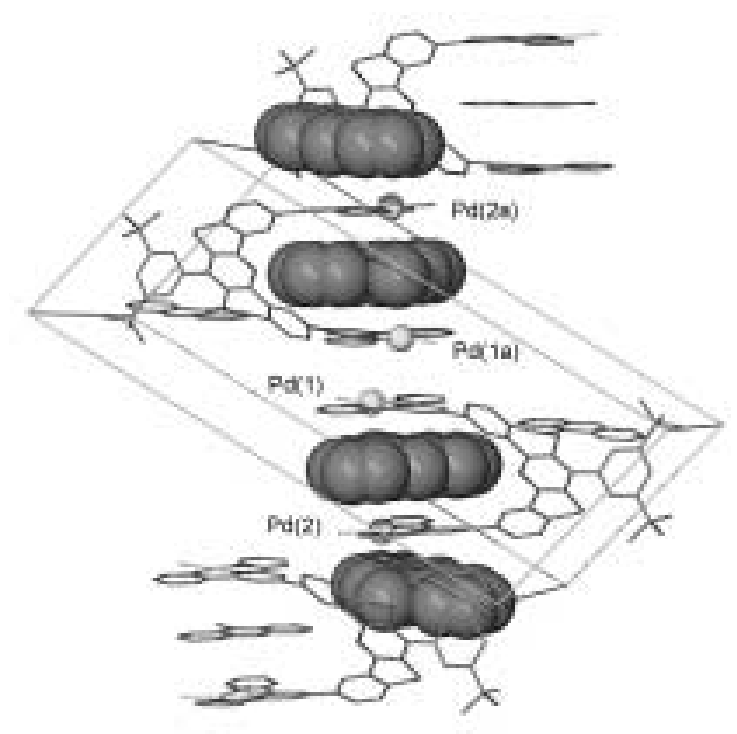

Figure 4 An illustration of the extended structure of [1 $(\mathrm{L}=\mathrm{Cl})]^{2+} \cdot 2(9-\mathrm{MA})$. The box is the unit cell, 9-MA molecules of the stack are shown as space-filling models and the terpy-Pd-Cl units are shown as stick models, as are all other molecules not involved in this stack. Palladium atoms in the stack are shown as spheres.

The guest-host results for $\mathbf{4}$ and $\mathbf{5}$ are unusual. Whereas the incarceration of 9-MA in the molecular clefts may not occasion surprise, the possibility of association of 9-MA with the outer faces of terpy-Pd-L units is unexpected. It is generally assumed that $\pi$-stacking occurs because of excited state exciton coupling mixing with the ground states ${ }^{9}$ and these attractive forces undoubtedly operate in the present cases. Because $\mathbf{4}$ and $\mathbf{5}$ are highly charged, in- 
duced dipoles may also be an important factor contributing to the stability of the adducts. It may be that induced dipole contributions are decisive in providing stability to 9-MA association with the outer faces of the terpy-Pd-L units. Thus, the present work provides evidence for guesthost associations which have not been commonly invoked and which may have an impact on the way association is interpreted.

\section{Acknowledgement}

This work was supported by grants from the Department of Energy.

\section{References and Notes}

(1) (a) Hagrman, P. J.; Hagrman, D.; Zubieta, J. Angew. Chem. Int. Ed. 1999, 38, 2638-2684. (b) Blake, A. J.; Champness, N. R.; Hubberstey, P.; Li, W.-S.; Withersby, M. A.; Schröder, M. Coord. Chem. Rev. 1999, 138, 117-138.

(2) (a) Hasenknopf, B.; Lehn, J. -M.; Boumediene, N.; DupontGervais, A.; Van Dorsselaer, A.; Kneisel, B.; Fenske, D. J. Am. Chem. Soc. 1997, 119, 10956-10962. (b) Hasenknopf, B.; Lehn, J. -M.; Boumediene, N.; Leize, E.; Van Dorsselaer, A. Angew. Chem. Int. Ed. Engl. 1998, 37, 3265-3268. (c) Garcia, A. M.; Romero-Salguero, F. J.; Bassani, D. M.; Lehn, J. -M.; Baum, G.; Fenske, D. Chem.-Eur. J. 1999, 5, 1803-1808. (d) Rojo, J.; Lehn, J. - M.; Baum, G.; Fenske, D.; Waldmann, O.; Müller, P. Eur. J. Inorg. Chem. 1999, 517-522.

(3) (a) Fujita, M. Acc. Chem. Res. 1999, 32, 53-61. (b) Fujita, M. Chem. Soc. Rev. 1998, 27, 417-425. Fujita, M.; Ogura, K. Coord. Chem. Rev. 1996, 148, 249-264. (c) Stang, P. J.; Olenyuk, B. Acc. Chem. Res. 1997, 30, 502-518. (d) Stang, P. J. Chem.-Eur. J. 1998, 4, 19-27.

(4) The preparation of the spacer-chelator complexes is provided elsewhere. Sommer, R. D.; Rheingold, A. L.; Goshe, A. J.; Bosnich, B. J. Am. Chem. Soc. 2001, 123, 3940-3952.

(5) (a) Hunter, C. A.; Sanders, J. K. M. J. Am. Chem. Soc. 1990, $112,5525-5534$.

(6) (a) Houlding, V. H.; Miskowski, V. M. Coord. Chem. Rev. 1991, 111, 145-152. (b) Bailey, J. A.; Miskowski, V. M.; Gray, H. B. Inorg. Chem. 1993, 32, 369-370. (c) Rice, S. F.; Miskowski, V. M.; Gray, H. B. Inorg. Chem. 1988, 27, 47044708. (d) Miller, J. R. J. Chem. Soc. 1961, 4452-4457.

(7) Representative procedure for the preparation of supramolecular rectangles. $\left[(2)\left(\mathrm{L}=\mathrm{CH}_{3} \mathrm{CN}\right)\right]\left(\mathrm{PF}_{6}\right)_{2}(0.0502$ $\mathrm{g}, 0.0277 \mathrm{mmol})$ was dissolved in acetonitrile $(10 \mathrm{~mL})$ in a 25 $\mathrm{mL}$ flask forming a yellow solution. To this solution was added 4,4'-dipyridyl ( $0.00433 \mathrm{~g}, 0.0277 \mathrm{mmol})$. The dipyridyl rapidly dissolved and the intensity of the color lightened. The reaction was stirred at room temperature for $1 \mathrm{~h}$. Half of the acetonitrile was removed in vacuo and the solution was vapor diffused with ether to yield the product as small yellow needles $(0.0481 \mathrm{~g}, 92.3 \%)$. Both molecular rectangles give very symmetrical ${ }^{1} \mathrm{H}$ NMR spectra. Both the spacer-chelators and 4,4'-dipyridyl groups of the rectangles have identical chemical shifts consistent with the $D_{2 h}$ point group. Physical measurements for 5. ${ }^{1} \mathrm{H}$ NMR $\left(\mathrm{CD}_{3} \mathrm{CN}, 500 \mathrm{MHz}\right): \delta 1.50(\mathrm{~s}$, $36 \mathrm{H}), 7.54(\mathrm{~d}, J=1.74,4 \mathrm{H}), 7.78-7.82(\mathrm{~m}, 16 \mathrm{H}), 7.90(\mathrm{t}$, $J=1.72,2 \mathrm{H}), 7.94(\mathrm{~d}, J=9.15,4 \mathrm{H}), 8.05(\mathrm{~d}, J=9.32,4 \mathrm{H})$, $8.42(\mathrm{~d}, J=8.25,4 \mathrm{H}), 8.48\left(\mathrm{dd}, J_{1}=1.81, J_{2}=7.67,4 \mathrm{H}\right)$, $8.54-8.59(\mathrm{~m}, 16 \mathrm{H}), 8.65(\mathrm{~d}, J=7.73,8 \mathrm{H}), 9.10(\mathrm{~s}, 8 \mathrm{H}), 9.49$ $(\mathrm{d}, J=6.34,8 \mathrm{H}), 10.57(\mathrm{~d}, J=1.94,4 \mathrm{H}) . \Lambda_{\mathrm{M}}=511 \Omega$ ${ }^{1} \mathrm{~cm}^{2} \mathrm{~mol}^{-1}$. Anal. Calcd for $\mathrm{C}_{150} \mathrm{H}_{118} \mathrm{~F}_{48} \mathrm{~N}_{18} \mathrm{P}_{8} \mathrm{Pd}_{4}: \mathrm{C}$, 47.94; $\mathrm{H}$, 3.16; N, 6.71. Found: C, 47.23; H, 3.13; N, 6.76. ESI-MS: a series of peaks were observed consistent with [M$\left.n\left(\mathrm{PF}_{6}\right)\right]^{n+} \cdot m\left(\mathrm{CH}_{3} \mathrm{CN}\right)(n=1-7, m=0,2)$ : for example, 402.4 $\left[\mathrm{M}-7\left(\mathrm{PF}_{6}\right)+2\left(\mathrm{CH}_{3} \mathrm{CN}\right)\right]$. Physical measurements for $4 .{ }^{1} \mathrm{H}$ NMR $\left(\mathrm{CD}_{3} \mathrm{CN}, 500 \mathrm{MHz}\right): \delta 1.40(\mathrm{~s}, 36 \mathrm{H}), 2.80(\mathrm{t}, J=7.08$, $8 \mathrm{H}), 3.08(\mathrm{t}, J=7.09,8 \mathrm{H}), 7.18(\mathrm{~d}, J=1.75,4 \mathrm{H}), 7.59(\mathrm{~d}$, $J=4.69,8 \mathrm{H}), 7.61(\mathrm{t}, J=1.78,2 \mathrm{H}), 7.68-7.71(\mathrm{~m}, 12 \mathrm{H}), 8.06$ $\left(\mathrm{dd}, J_{1}=2.06, J_{2}=6.66,4 \mathrm{H}\right), 8.38(\mathrm{~d}, J=6.57,8 \mathrm{H}), 8.42(\mathrm{td}$, $\left.J_{1}=1.37, J_{2}=8.86,8 \mathrm{H}\right), 8.47(\mathrm{~d}, J=7.75,8 \mathrm{H}), 8.76(\mathrm{~s}, 8 \mathrm{H})$, $9.28(\mathrm{~d}, J=6.44,8 \mathrm{H}), 9.43(\mathrm{~d}, J=1.97,4 \mathrm{H}) . \Lambda_{\mathrm{M}}=527 \Omega^{-1}$ $\mathrm{cm}^{2} \mathrm{~mol}^{-1}$. Anal. Calcd for $\mathrm{C}_{150} \mathrm{H}_{126} \mathrm{~F}_{48} \mathrm{~N}_{18} \mathrm{P}_{8} \mathrm{Pd}_{4}: \mathrm{C}, 47.84 ; \mathrm{H}$, 3.37; N, 6.69. Found: C, 47.99; H, 3.36; N, 6.80. ESI-MS: a series of peaks were observed consistent with [M$\left.n\left(\mathrm{PF}_{6}\right)\right]^{\mathrm{n}+} \cdot m\left(\mathrm{CH}_{3} \mathrm{CN}\right)(n=1-7, m=0,2)$ : for example, 1110.3 $\left[\mathrm{M}-3\left(\mathrm{PF}_{6}\right)\right] .^{3+}$

(8) The procedure for stoichiometry determination employed for 5 is representative. A series of $2.43 \mathrm{mM}$ solutions of $\mathbf{5}$ in $\mathrm{CD}_{3} \mathrm{CN}$ containing varying amounts of 9-methylanthracene, ranging from $1.26 \mathrm{mM}$ to $104 \mathrm{mM}$, were prepared. The solutions were permitted to equilibrate for $2 \mathrm{~h}$ before they were examined by ${ }^{1} \mathrm{H}$ NMR spectroscopy and UV-VIS spectrometry. The host alone is yellow in color and the guest alone is nearly colorless. The host-guest mixtures varied from yellow-orange at low concentrations of guest to red at high concentrations of guest. The maximum chemical shift change for any proton of the host was $0.94 \mathrm{ppm}$. Several other protons of the host had maximum changes of approximately $0.5 \mathrm{ppm}$. The maximum chemical shift change observed for the guest was $0.25 \mathrm{ppm}$, with several other chemical shifts changing by about $0.2 \mathrm{ppm}$. The stoichiometry was determined by the "mole ratio" method, as described by Meyer and Ayres, to be five guest molecules per one host molecule, by plotting the change in chemical shift versus the mole ratio of guest to host for several protons of each (Figure 2). Meyer, A. S.; Ayres, G. H. J. Am. Chem. Soc. 1957, 79, 49-53.

(9) (a) Murrell, J. N.; Tanaka, J. Mol. Phys. 1964, 45, 363.

(b) Lim, E. C. Acc. Chem. Res. 1987, 20, 8-17.

Article Identifier:

1437-2096,E;2001,0,SI,0941,0944,ftx,en;Y01501ST.pdf 